\title{
The Global Pandemic - A blessing in disguise for Medical Education innovations.
}

The Editorial of the January 2021 issue of SEAJME highlighted the need for innovative approaches when facing challenges in medical education in the new normal (Karunathilake \& de Abrew, 2021). The present issue consists of a compilation of papers reporting on diverse innovations and interventions in medical education that have been planned, developed and implemented during these unprecedented times.

The lead article of this issue titled Training Medical Students as COVID-19 first contact responders: Integrating Telemedicine and Medical Education during a Health System Crisis in Sri Lanka (Karunathilake et al., 2021) discusses an innovative response that combines public health, medical informatics and volunteerism. This intervention is a unique example of integrating medical education with telemedicine during COVID-19. Considering the imminent care needs during the pandemic, the authors discuss harnessing support from all stakeholders including sectors previously underutilized.

Jayararathne and Pilapitiya (2021) discuss the Educational Response to COVID-19: Faculty of Medicine and Allied Sciences, Rajarata University of Sri Lanka. This perspective article discusses a systematic approach for teaching/learning, assessment and faculty development as a response to COVID-19, along the themes of leadership/management, use of technology in teaching/learning and developing physical and human resources. In their short communication, Udgiri and Biradar (2021) evaluate the virtual classroom experience, one of the most widely used adaptations during the pandemic. They report medical students' perceptions about their teaching/learning experiences during the lockdown, and summarize the reported advantages and disadvantages.

A practical clinical training course model for use during the COVID-19 pandemic is reported by Tan and Manohararaj (2021), in the section on Medical Education in Practice. They describe the design and implementation of a clinical course model designed to lower the risks of transmission between and beyond the participants, with special emphasis on ease of implementation and efficient use of resources. In the next practice article, Evans \& Noone (2021), discuss teaching medical students during the Surgery placement amidst the COVID19 pandemic, and share the lessons learned so far. Innovative steps are taken to optimize undergraduate teaching, balancing the need for safety and limiting viral transmission, while maximising clinical experience and learning. The authors discuss the how the COVID-19 pandemic has forced widespread changes to the way in which medical students receive teaching and suggest to ways to maximise learning opportunities during hospital placements.

The comparative study of online learning of medical procedures via video versus text modalities by Kritsanaviparkporn et al (2021), compared the efficacy of utilizing video and text modalities in knowledge acquisition of a new clinical procedure in medical students during the COVID-19 lockdown. Interestingly, the intervention is carried out entirely online, with student participants randomized to receive one of the interventions. They recommend the use of video tutorials during the online learning phase, to ensure students have a solid knowledge foundation ready for when clerkship resumes.

DOI: http://doi.org/10.4038/seajme.v15i2.377

(C) SEAJME. This is an Open Access article distributed under the terms of the Creative Commons Attribution License (http://creativecommons.org/licenses/by/4.0/), which permits unrestricted use, distribution, and reproduction in any medium, provided the original author and source are credited South-East Asian Journal of Medical Education 
This brief summary provides a primer to the wide range of interventions and opportunities that have opened up during the new normal of medical education in the midst of COVID-19.

Professor I.M. Karunathilake and Dr. A. de Abrew

Department of Medical Education, Faculty of Medicine, University of Colombo, Sri Lanka.

\section{References}

Evans W and Noone, TM. (2021) Teaching medical students on Surgical placement during the COVID19 pandemic, lessons learned so far. South-East Asian Journal of Medical Education, 15(2).

Jayararathne YGSW and Pilapitiya SD (2021) Educational Response to COVID- 19: Faculty of Medicine and Allied Sciences, Rajarata University of Sri Lanka, South-East Asian Journal of Medical Education, 15(2).

Karunathilake IM. (2020) Beyond 2020: Moving Towards New Normal in Medical Education. South-East Asian Journal of Medical Education, 14(2).

Karunathilake, I.M., Dissanayake, V.H.W., Yasawardena, S., Abegunawardena. A., Raviraj, S., Wijesinghe. P.S., Anthony, A.A., Wijesinghe, R.A.N.K., Bowatte, S., Wickramaratne, N., Pathirana, K.D., Pilapitiya, S., Edirisinghe, S., Hettiarachchi, D., Kohombange, C. \& Olipeliyawa, A. (2020). The New Normal of Medical Education - Challenges and Opportunities. South-East Asian Journal of Medical Education, 14(1).

Karunathilake, I.M., Edirisinghe, E.A.S.T., Hettiarachchi, D., Perera, B.J.C., Hamdani, A., Kohombange, C., Herath, T., Amarasiri, M., Randenikumara, S., Mudiyanse, R., Senanayake, D., Ihsan, R., Guruge, K., Ragunathan, MK (2021) Training Medical Students as COVID 19 first contact responders: Integrating Telemedicine and Medical Education during a Health System Crisis in Sri Lanka, South-East Asian Journal of Medical Education, 15(2).

Karunathilake IM and de Abrew A (2021). Medical Education during Challenging Times. South-East Asian Journal of Medical Education, 15(1), pp.1-2.

Kritsanaviparkporn C, Kitcharoen N, Yimcharoen N, Thaweesuk S, Maneerit S and Treesirichod A (2021) A comparative study of online medical procedure learning via video versus text modalities during the COVID-19 pandemic, South-East Asian Journal of Medical Education, 15(2).

Tan YJ and Manohararaj N (2021) A practical clinical training course model for use during the COVID19 pandemic Medical Education in Practice Singapore, South-East Asian Journal of Medical Education, 15(2).

Udgiri and Biradar (2021) Medical student's perception about virtual classroom during lockdown -A cross-sectional study, South-East Asian Journal of Medical Education, 15(2) 